\title{
Breath Stable Isotope Analysis Serves as a Non-invasive Analytical Tool to Demonstrate Dietary Changes in Adolescent Students Over Time
}

\author{
Christy J. Mancuso ${ }^{1,2 *}$, Collette M. Cornwall ${ }^{3 t}$, Swede Robinson ${ }^{3+}$, \\ Luciano O. Valenzuela ${ }^{2,4}$ and James R. Ehleringer ${ }^{2}$
}

${ }^{1}$ Department of Biology, University of New Mexico, Albuquerque, NM, United States, ${ }^{2}$ School of Biological Sciences, University of Utah, Salt Lake City, UT, United States, ${ }^{3}$ Highland High School, Salt Lake City School District, Salt Lake City, UT, United States, ${ }^{4}$ Consejo Nacional de Investigaciones Cientificas y Técnicas, Facultad de Ciencias Sociales, Universidad Nacional del Centro de la Provincia de Buenos Aires, Unidad de Enseñanza Universitaria Quequén, Quequén, Argentina

OPEN ACCESS

Edited by:

Joseph Skulan,

Independent Researcher, Petersburg,

United States

Reviewed by:

Ekaterina Kolesanova,

Russian Academy of Medical

Sciences (RAMS), Russia

Lakshmy Ramakrishnan,

All India Institute of Medical

Sciences, India

*Correspondence:

Christy J. Mancuso

mancusoc@unm.edu

tThese authors have contributed equally to this work

Specialty section:

This article was submitted to

Translational Medicine,

a section of the journal

Frontiers in Medicine

Received: 19 April 2021 Accepted: 17 December 2021

Published: 25 January 2022

Citation:

Mancuso CJ, Cornwall CM Robinson S, Valenzuela LO and Ehleringer JR (2022) Breath Stable

Isotope Analysis Serves as a

Non-invasive Analytical Tool to Demonstrate Dietary Changes in Adolescent Students Over Time.

Front. Med. 8:697557.

doi: 10.3389/fmed.2021.697557
Concern about adolescent diets, obesity, and the associated health risks have been growing in the United States. This inspired former First Lady Michelle Obama to spearhead the Healthy Hunger-Free Kids Act (HHFKA), which made changes to the national school lunch program by increasing servings of whole grains, fruits, and vegetables. Our study examined the variability of student carbohydrate sources throughout the day and before and after the implementation of HHFKA using a stable isotope dietary biomarker. This method uses carbon stable isotope values of exhaled $\mathrm{CO}_{2}$ breath $\left(\delta^{13} \mathrm{C}_{\text {breath }}\right)$ and provides a quantitative, non-invasive measure. $\delta^{13} \mathrm{C}_{\text {breath }}$ samples were collected throughout the day from students $(n=31)$ that attended a public high school in Salt Lake City, UT. $\delta^{13} \mathrm{C}_{\text {breath }}$ measurements reflected the short-term carbohydrate inputs from the previous meal. Carbohydrate sources were not consistent throughout the day; most students had their lowest inputs of corn/sugar-based carbohydrates after lunch. We compared our results with an earlier study that had been conducted pre-HHFKA. After-lunch $\delta^{13} \mathrm{C}_{\text {breath }}$ values decreased significantly between the two time points, suggesting an increase in whole grain, fruit, and vegetable carbohydrates in the lunch program. Our results demonstrated that $\delta^{13} \mathrm{C}_{\text {breath }}$ measurements provide a valuable tool to examine carbohydrate sources in an individual's diet throughout the day. We believe that this tool could be beneficial to studies examining the relationship between sugar sweetened beverages, added sugars, and refined carbohydrates and health outcomes like diabetes and obesity in both adolescent and adult populations.

Keywords: stable isotopes, diet, exhaled breath $\mathrm{CO}_{2}$, high school students, Healthy Hunger-Free Kids Act (HHFKA)

\section{INTRODUCTION}

Childhood obesity has been a growing concern in the United States and over the past 30 years has quadrupled among adolescents (1). Studies have shown that diets rich in carbohydrates and refined sugars have contributed in the rise in obesity and cardiovascular disease (2-5). Having precise dietary measurements are critical to these studies and most tools for dietary assessments 
rely on self-reporting and recall of food items and quantities consumed. These assessment tools are widely used in nutrition and diet studies and have been successfully applied in understanding habitual diets in large populations; however, they require literate populations that can accurately recall the types and quantities of foods consumed, may have high participant burdens, and can be resource intense (6-10). Having a quantitative and objective biomarker of diet would be an asset to these dietary assessments and recall methodologies. Here we describe the use of a stable isotope dietary biomarker that is noninvasive, cost effective, and provides quantitative outputs that are free of reporting biases related to gender, age, or ethnicity.

Stable isotope biomarkers have readily been used to learn about diets in many disciplines ranging from animal ecology to anthropology (11-15). They are also gaining credence and popularity among nutrition and health research $(10,16,17)$. In particular, carbon $\left(\delta^{13} \mathrm{C}\right)$ isotope ratios have been used because they display predictable and natural patterns that are linked to protein, carbohydrate, and lipid consumption (18, 19). Carbon in food is derived from atmospheric $\mathrm{CO}_{2}$ that is fixed in organic molecules through the process of photosynthesis in plants. Differences in plant photosynthetic processes $\left(\mathrm{C}_{3}\right.$ or $\left.\mathrm{C}_{4}\right)$ generates most of the variation that is found in our food (20) and has allowed us to differentiate diets among populations $(18,21)$. These processes impart unique non-overlapping $\delta^{13} \mathrm{C}$ values for $\mathrm{C}_{3}$ (vegetables, grains, fruits; $\mathrm{C}_{3}$ : -20 to $-30 \%$,) and $\mathrm{C}_{4}$ (corn, sorghum, sugarcane; $\mathrm{C}_{4}$ : -16 to $-10 \%$ ) foods and relate to the dietary proportions of these plants that have been consumed directly by an individual or indirectly as animal feed (19-22).

In the United States corn, sugar cane, and their respective derivatives (ex. high fructose corn syrup) are some of the most wildly consumed $\mathrm{C}_{4}$ food products. They are integrated into human tissues through the consumption of refined carbohydrates (ex. candies, cookies), sweetened beverages, and livestock that are fed corn-based feed (23-25). Distinct differences in the $\delta^{13} \mathrm{C}$ values of these $\mathrm{C}_{4}$ sweetened foods allows them to be identified from $\mathrm{C}_{3}$ carbohydrate sources (25). While $\mathrm{C}_{4}$ food products (corn, millet, sorghum) are not necessarily unhealthy, the byproducts or derivatives are added to beverages and foods have been associated with increased caloric intake, weight gain, and sugar consumption that can have deleterious health outcomes $(9,23,26)$. These findings have sparked the interest of medical researchers, particularly the analysis of $\delta^{13} \mathrm{C}$ values to examine elevated sugar intake in youth and adolescent populations. Many of these studies have relied on blood samples collected from a routine fingerstick. While these collection methods are minimally invasive, they still inflict discomfort to the study subject and increase potential exposure to blood borne pathogens to research personnel $(9,10,23)$. Here we propose the use of exhaled breath $\mathrm{CO}_{2} \delta^{13} \mathrm{C}$ (here forward $\delta^{13} \mathrm{C}_{\text {breath }}$ ) measurements, as another quantitative biomarker to examine dietary changes that would be pain free, non-invasive, and reduced risk to pathogens.

There has a been a long history of $\delta^{13} \mathrm{C}_{\text {breath }}$ analyses. Early studies were interested in understanding the baseline variation in breath $\delta^{13} \mathrm{C}$ for metabolic labeling studies (27). Recent, analytical advancements have sparked a renewed interest in $\delta^{13} \mathrm{C}_{\text {breath }}$ measurements for metabolic and dietary studies (16, 28-31).
The analysis of $\delta^{13} \mathrm{C}_{\text {breath }}$ has been of interest to examine carbohydrate intake over short time scales (hours) and may reflect foods that have been immediately eaten (carbohydrates and simple sugars) or stored reserves (lipids) $(31,32)$. Recently, O'Brien et al. examined using $\delta^{13} \mathrm{C}_{\text {breath }}$ as a marker of short term added sugar intake in adult participants in a controlled setting (16).

Our interest in the analysis of $\delta^{13} \mathrm{C}_{\text {breath }}$ measurements in adolescent high schoolers were fueled by the growing concern of excess sweeteners in their diets, the deleterious health outcomes associated with obesity, and the implementation of the Healthy Hunger-Free-Kids Act (HHFKA) in 2012. This program was spearheaded by former First Lady Michelle Obama and promoted increased servings of whole grains, fruits, and vegetables in the national school lunch program (33). The goal of our study was to analyze $\delta^{13} \mathrm{C}_{\text {breath }}$ from high school students in Salt Lake City, UT to examine (a) broad carbohydrate sources of adolescent students throughout the day, and (b) to compare the findings of our 2016 adolescent population to that of Valenzuela et al.'s 2009-2010 population to examine if the $\delta^{13} \mathrm{C}_{\text {breath }}$ in high school students in the Salt Lake City school district have changed in conjunction with the implementation of the HHFKA.

\section{METHODS}

Thirty-one student volunteers were recruited from a public high school (grades 10-11) in Salt Lake City, Utah in 2016. Breath samples, demographic information (sex and participation in school lunch), and an anonymous diet survey were collected from volunteers. The University of Utah's Institutional Review Board approved this study (IRB 00035524) and parents/legal guardians and students provided written consent to participate and could choose which sample(s) and demographic information they provided. Hence, the sample sizes of different variables. To draw comparisons to our study population we examined a dataset of $\delta^{13} \mathrm{C}_{\text {breath }}$ samples from students in a different public high school in the Salt Lake City school district (grade 10, $n=33$ ) (University of Utah's Institutional Review Board approved, IRB 00032797) that were collected in 2009-2010 and were part of a larger study from Valenzuela et al. (31).

\section{Breath Samples}

In our study three breath samples were requested from each volunteer to measure after breakfast $(\mathrm{AB})$, after lunch $(\mathrm{AL})$, and after dinner $(\mathrm{AD}) \delta^{13} \mathrm{C}_{\text {breath}}$. Students were directed to take breath measurements in a 1-to 2 -h window following their meal. Volunteers were provided with straws and labeled Exetainer tubes (Labco, United Kingdom) and were instructed to inhale atmospheric air and exhale air through the coffee straw into the tube for $1 \mathrm{~min}$ and immediately cap the sample and return it to school the next day. $\mathrm{AB}$ and $\mathrm{AD}$ samples were collected at home and AL samples were collected at the school in a 1-to 2hour window following lunch. All samples were collected and stored at room temperature during the school week (Tuesday - Thursday) to ensure that breath samples could be collected by teachers and delivered to the University of Utah within a 24-48 h collection window to be analyzed. The majority of the 
$\mathrm{AL}$ and $\mathrm{AD}$ samples from each volunteer were sampled on the same day; however, this was not always possible (i.e., students would forget to sample $\mathrm{AD}$ breath and sample would be taken the following evening). AB samples were collected on a different day. Although breath samples were taken on different days, we assumed that overall food choices during this time would remain consistent. Anonymous survey responses from participating students allowed us to understand habitual eating habits of the study group (Supplementary Table 1) and based upon their responses we felt that broad carbohydrate choice was consistent over the sampling period. Additionally, previous work examining breath stable isotopes found a significant covariation between breath isotopes and food based questionnaires of similarly aged students, suggesting that there may be temporal stability in the consumption of carbohydrate sources (31).

Breath samples from volunteers were analyzed at the Stable Isotope Ratio Facility for Environmental Research (SIRFER) at the University of Utah within $24-48 \mathrm{~h}$ of collection. Breath samples were measured using an autosampler connected to an isotope ratio mass spectrometer (Finnigan Delta Plus IRMS) via Thermo Finnigan Gasbench II (Thermo Fisher, Bremen, Germany). Breath samples and internal standards, which had previously been characterized relative to an international ${ }^{13} \mathrm{C}$ standard, were analyzed in triplicate. $\delta^{13} \mathrm{C}$ measurements of $\mathrm{AB}$, $\mathrm{AL}$, and $\mathrm{AD}$ breath samples were analyzed alongside three inhouse $\mathrm{CO}_{2}$ reference gases with isotope values of $+16.2,-6.0$, and $-42.6 \%$. The analytical precision $(1 \sigma)$, based on repeated measurements of these references, was $0.16 \%$. Results for $\delta^{13} \mathrm{C}$ values are presented on the Vienna Pee Dee Belemnite scale. Stable isotope ratios are reported using the standard $\delta$-notation relative to an international standard in units per mil (\%o) using the following: $\delta \mathrm{X}=\left(\mathrm{R}_{\text {sample }} / \mathrm{R}_{\text {standard }}-1\right) * 1000$, where $\mathrm{X}$ is the isotope of interest, $\mathrm{R}_{\text {sample }}$ and $\mathrm{R}_{\text {standard }}$ are the molar ratios of the heavy to the light isotopes (e.g., ${ }^{13} \mathrm{C} /{ }^{12} \mathrm{C}$ ) of the sample and international standard, respectively.

We compared our $\delta^{13} \mathrm{C}_{\text {breath }}$ samples with that of the high school population described in Valenzuela et al. (31). In brief, they collected two breath samples from each participant, one in the morning (AM) before breakfast and an $\mathrm{AL}$ breath sample that was collected in a 1-to-2-h window following lunch. Samples were collected in foil balloons and analyzed on the same day at the SIRFER facility (34). Six hundred microliters of exhaled breath samples were removed from balloons using a gas tight syringe with a pressure locking valve (Pressure-Lok, Baton Rouge, Louisiana) and injected onto a gas chromatography column coupled to a Finnigan Delta Plus IRMS (Thermo Fisher, Bremen, Germany) operating in continuous flow mode. Similar to our study breath samples were analyzed alongside in-house $\mathrm{CO}_{2}$ reference gases with isotope values of +15.5 and $-10.0 \%$. The analytical precision $(1 \sigma)$, based on repeated measurements of these references, was $0.15 \%$ (31).

\section{Statistics}

Statistical significance and graphic output were generated using Prism v9.0 (GraphPad Software). Data were summarized as mean \pm standard deviation (SD). Normality of distributions were examined using the Shapiro-Wilks test. Exhaled breath samples throughout the day from all participants were analyzed using an Ordinary one-way ANOVA as we had unequal number of samples at each time point. Sex and school lunch participation comparisons were analyzed using an unpaired $t$-test. To examine the relationship between $\delta^{13} \mathrm{C}$ values of exhaled breath $\mathrm{CO}_{2}$ after each meal Pearson correlations were made from $\mathrm{AB}$ vs. $\mathrm{AL}, \mathrm{AL}$ vs. $\mathrm{AD}$, and $\mathrm{AD}$ vs. $\mathrm{AB}$. Comparisons between $\delta^{13} \mathrm{C}$ exhaled breath samples pre- and post- HHFKA were assessed using an unpaired $t$-test test. Results were considered significant at $p<0.05$.

\section{RESULTS}

Thirty-one high school students (grades 10 and 11) in the Salt Lake City school district participated in this study (Table 1); 18 were male and 13 were female; $51 \%$ of the students reported that they participated in the school lunch program. While we did not record student ethnicity, the high school that we worked with had a predominately non-Hispanic White $(49 \%)$ and Hispanic (21\%) student population at time of sample collection (35). We analyzed $\delta^{13} \mathrm{C}_{\text {breath }}$ samples measurements $\mathrm{AB}(n=31)$, $\mathrm{AL}(n$ $=24)$, and $\operatorname{AD}(n=22)$. Breath sample numbers varied, as volunteers were not required to participate in every collection and could choose to leave the study at any time. Breath isotope samples were normally distributed (Shapiro-Wilk test, $P>0.5$ for all variables, $\mathrm{AB} \delta^{13} \mathrm{C}_{\text {breath }} \mathrm{W}=0.97, P=0.62$; $\mathrm{AL} \delta^{13} \mathrm{C}_{\text {breath }}$ $\mathrm{W}=0.95, P=0.26$; $\left.\mathrm{AD} \delta^{13} \mathrm{C}_{\text {breath }} \mathrm{W}=0.96, P=0.57\right)$. Samples from our study were compared to 33 high school students from grade 10 in a different high school in the Salt Lake City school district that were collected in 2009-2010 as part of the Valenzuela et al. study (Table 1). These students were part of a larger study population that included students from grades 5-10; however, we have focused on students from grade 10 , as they are most similar to our study population. From the population in the Valenzuela study, 16 participants were male and 19 were female; $63 \%$ were non-Hispanic White and $31 \%$ of the students were Hispanic. $\delta^{13} \mathrm{C}$ measurements of AM and $\mathrm{AL}(n=33)$ exhaled $\mathrm{CO}_{2}$ breath

TABLE 1 | Summary of study population demographics.

2016 population

2009-2010 population

\section{Characteristic}

Total participants
31

Sex

Male

Female

Participation in school lunch

$\%$ Yes

Race/ethnicity

$\%$ Non-hispanic white

$\%$ Hispanic
Samples from 2009-2010 study population were collected and further described in Valenzuela et al. (31).

* Race/ethnicity was not collected for 2016 study population, values listed were reported for the entire high school population (35). 
samples were analyzed, and all breath samples were normally distributed (Shapiro-Wilk test, $P>0.5$, AM $\delta^{13} \mathrm{C}_{\text {breath }} \mathrm{W}=0.97$, $P=0.62, \mathrm{AL} \delta^{13} \mathrm{C}_{\text {breath }} \mathrm{W}=0.97, P=0.53$ ).

\section{Variation in Breath $\delta^{13} \mathrm{C}$ Throughout the Day}

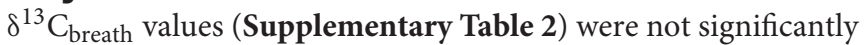
different among demographic variables (sex and school lunch participation) or across the different time points $(\mathrm{AB}, \mathrm{AL}$, or $\mathrm{AD})$ for the entire study population $(n=31)$. The variation in sample number for each time point could have contributed to these findings. To ensure that an equal number of samples were present at each time point, we examined samples only from study subjects that contributed breath samples at all time points $(n=19)$ for the following analyses. Breath samples were not always collected over sequential days, but we made the assumption that dietary choices were similar on a day-to-day basis based on anonymous survey responses from students, interactions with teachers, and previous studies (31). We compared the change in $\delta^{13} \mathrm{C}_{\text {breath }}$ after each meal and found there were positive correlations between all analyses (Figure 1), with significant relationships for analyses comparing $\mathrm{AL}$ vs. $\mathrm{AD}(p=0.004$, Pearson $r=0.631)$ and $\mathrm{AD}$ vs. $\mathrm{AB}(p=0.050$, Pearson $r=0.456)$. We did not find significant correlations between $\mathrm{AB}$ vs. AL ( $p=0.055$, Pearson $r=0.447$ ). Examination of the difference between the after-meal breath isotope values, relative to the earlier meal revealed that at the individual level few volunteers maintained a constant isotope value throughout the day. Fifty three percent of $\mathrm{AL} \delta^{13} \mathrm{C}_{\text {breath }}$ samples were more negative relative to $A B$ (Figure 1A). Fortyseven percent of $\mathrm{AL} \delta^{13} \mathrm{C}_{\text {breath }}$ samples were more negative relative to $\mathrm{AD}$, while $21 \%$ remained consistent between $\mathrm{AL}$ and $\mathrm{AD}$ samples (Figure 1B). These findings suggest that for most of the study subjects lunch had the most negative $\delta^{13} \mathrm{C}_{\text {breath values }}$ and would be consistent with greater proportions of $\mathrm{C}_{3}$ foods.

\section{Comparison of $\delta^{13} \mathrm{C}$ Breath Isotopes Pre- and Post-HHFKA}

Lastly, we compared our $\mathrm{AL} \delta^{13} \mathrm{C}_{\text {breath }}$ values with samples that were collected as part of the Valenzuela et al. study to examine changes to $\delta^{13} \mathrm{C}_{\text {breath }}$ values pre- and post- HFFKA implementation. Examination of the $\delta^{13} \mathrm{C}_{\text {breath }}$ values between the two studies highlighted a shift in the AL $\delta^{13} C_{\text {breath }}$ samples being more negative post-HHFKA [Figure 2, $p<0.001$, unpaired $T$-test, pre- $(n=33)$ and post- $(n=24)]$. While our study did not record ethnicity from study subjects, $31 \%$ of the breath samples from the Valenzuela study came from Hispanic students, where they noted a significant elevation in sweetened beverage servings per week compared to the non-Hispanic White students across all participants in their study (31). The high school that our students attended had a $21 \%$ Hispanic student population. To potentially mitigate against the $\mathrm{C}_{4}$ bias that could exist in the Hispanic population from the Valenzuela study, we also compared the $\delta^{13} \mathrm{C}_{\text {breath }}$ samples from only the non-Hispanic White students $(n=22)$ to our study subjects $(n=24)$ and we still saw that $\delta^{13} \mathrm{C}_{\text {breath }}$ samples were more negative post-HHFKA $(p=0.0009$, unpaired $t$-test). We also compared students in our population
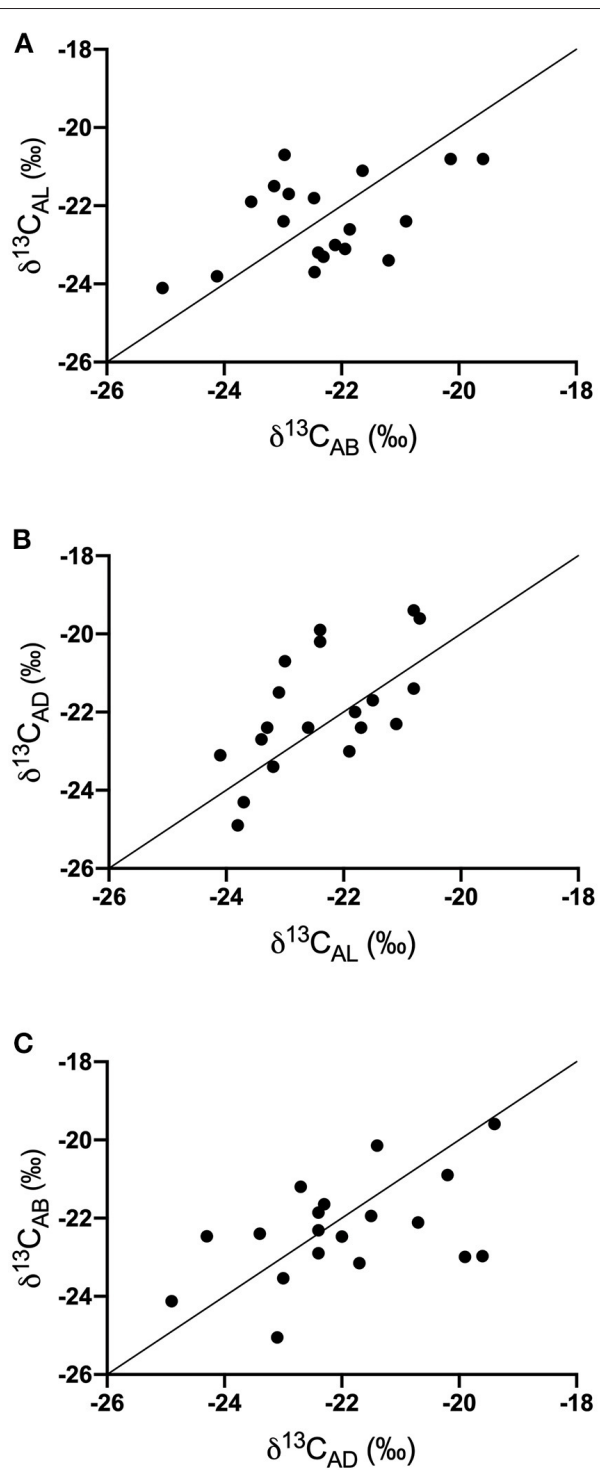

FIGURE 1 | Covariation of $\delta^{13} \mathrm{C}$ values of exhaled breath samples throughout the day (A) AB vs. AL, (B) AL vs. AD, and (C) AD vs. AB. Solid line represents the $1: 1$ line.

that ate school lunch $(n=12)$ and the non-Hispanic White students $(n=22)$ in the Valenzuela study and $\delta^{13} \mathrm{C}_{\text {breath samples }}$ were still more negative post-HHFKA ( $p=0.0026$, unpaired $t$ test). Lastly, we examined differences between the AM breath samples collected from Valenzuela et al. to our other time points and found that there were statistical differences between the two studies (AM vs. $A B, p=0.0003$, unpaired $t$-test and $A M$ vs. $A D$, $p=0.0038$, unpaired $t$-test).

\section{DISCUSSION}

This study has demonstrated that $\delta^{13} \mathrm{C}_{\text {breath }}$ measurements can be used as a valuable non-invasive tool to examine recent carbohydrate consumption in an individual's diet throughout the 


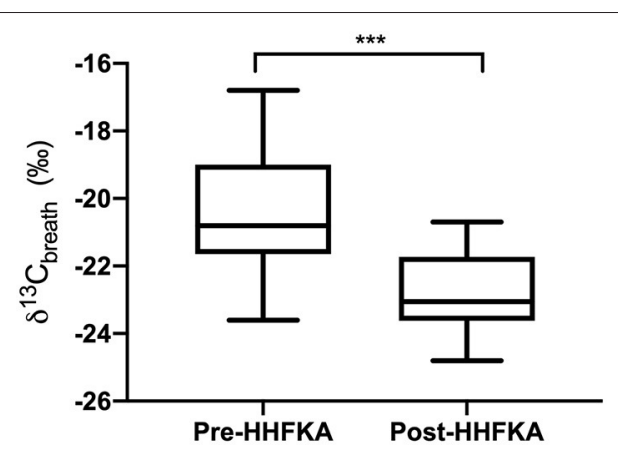

FIGURE 2 | After lunch carbon isotope values of exhaled breath display differences pre- and post HHFKA. Box and whiskers plot of carbon isotope values of exhaled breath $\mathrm{CO}_{2}$ collected after lunch from high school students (grades 10-11) before the Healthy, Hunger Free Kids Act (31); Pre-HHFKA, $n=$ 33 and after Post-HHFKA, $n=24 .{ }^{\star \star \star} p<0.001$, unpaired $t$-test.

day. Our study focused on samples from students after each meal to look at the variability in $\delta^{13} \mathrm{C}_{\text {breath }}$ values throughout the day. We found that $\delta^{13} \mathrm{C}_{\text {breath }}$ samples broadly quantified dietary inputs from carbohydrate sources over a period of hours. When we examined the $\delta^{13} \mathrm{C}_{\text {breath }}$ samples throughout the day among all of our study participants $(n=31)$, we did not find significant differences in the $\delta^{13} \mathrm{C}_{\text {breath }}$ values across the collection time points (Supplementary Table 2). Our results could support two conclusions (1) that as a population our students consumed similar carbohydrate sources throughout the day or (2) that previous meals could be influencing the $\delta^{13} \mathrm{C}_{\text {breath }}$ values at the different time points. There has been evidence that $\delta^{13} \mathrm{C}_{\text {breath }}$ measurements are representative of the most recent carbohydrate sources that an individual has consumed (23), but how recent may depend on isotopic turnover and the use of internal sources (32).

Studies from Scholler et al. and O'Brien et al. have provided evidence for the rapid utilization of carbohydrates in $\delta^{13} \mathrm{C}_{\text {breath }}$ measurements. Scholler et al., found that exhaled breath $\mathrm{CO}_{2}$ in infants being fed a glucose-amino acid mixture immediately began oxidizing carbohydrate sources and that their average $\delta^{13} \mathrm{C}$ values were similar to that of the glucose solution (27). Similarly, O'Brien et al. found that $\delta^{13} \mathrm{C}_{\text {breath }}$ in healthy adults fed a diet of increased added sugar displayed changes in their $\delta^{13} \mathrm{C}_{\text {breath }}$ within $2 \mathrm{~h}$ of a meal. They also examined $\delta^{13} \mathrm{C}_{\text {breath }}$ samples from healthy adult participants $(n=3)$ every 10 min following a meal high in added sugar. $\delta^{13} \mathrm{C}_{\text {breath }}$ samples rapidly increased over the first hour, remained steady for $2 \mathrm{~h}$, and declined an hour before lunch (16). While both studies agree that immediate $\delta^{13} \mathrm{C}_{\text {breath }}$ measurements reflect recently consumed carbohydrates and simple sugars, their findings differ on the amount of time that a previous meal could influence the subsequent meal $\delta^{13} \mathrm{C}_{\text {breath }}$ values. Scholler found that labeled glucose and sugars peaked in breath ${ }^{13} \mathrm{CO}_{2}$ excretion around $4 \mathrm{~h}$ and remain in the breath for up to $8 \mathrm{~h}$ (27). While the O'Brien study found that following a meal $\delta^{13} \mathrm{C}_{\text {breath }}$ peaked after $2 \mathrm{~h}$ and decreased $4 \mathrm{~h}$ after the meal; however $\delta^{13} \mathrm{C}_{\text {breath }} 4 \mathrm{~h}$ post meal did not return to the pre-feeding values, which could suggest some carry over to the next meal (16).

It is likely that our results from our entire study population are a mix of both immediate utilization of carbohydrates from the most recent meal and potentially some carry over from the prior meal. Both studies showed there was rapid incorporation of carbohydrates from the consumed meal that peaked within $1-2 \mathrm{~h}$, like our breath collection time points. It is possible that residual carbon from the previous meal could be present in our $\mathrm{AL}$ or $\mathrm{AD}$ samples and contribute to the similarity in the $\delta^{13} \mathrm{C}_{\text {breath }}$ values of our entire study population. However, it seems that our samples are more like O'Brien et al., as both study subjects consumed dietary foods opposed to glucose solutions. While we cannot exclude the potential of some residual carbon from the previous meal it seems unlikely to have had a major impact on the $\delta^{13} \mathrm{C}_{\text {breath }}$ value since meal breath samples were taken well-after the 4-h post-meal time point (16). Additionally, $\delta^{13} \mathrm{C}_{\text {breath }}$ values at the individual level support the O'Brien study's time period as we saw that among individual students $\delta^{13} \mathrm{C}_{\text {breath }}$ values changed throughout the day. Specifically, that $\mathrm{AL} \delta^{13} \mathrm{C}_{\text {breath }}$ samples relative to either $\mathrm{AB}$ or $\mathrm{AD}$ meals suggested that that more $C_{3}$ carbohydrate sources were consumed at lunch.

To examine the potential changes associated with the implementation of HHFKA, we compared the $\delta^{13} \mathrm{C}_{\text {breath }}$ samples (post-HHFKA) from our population (2016) to the high school population described in Valenzuela et al.'s 2009-2010 study (preHHFKA) (31). $\delta^{13} \mathrm{C}_{\text {breath }}$ samples pre-HHFKA were significantly higher and suggest that students consumed more $\mathrm{C}_{4}$ processed carbohydrates that had added sugars (i.e., corn or cane sugars) during their lunch compared to observations in our study. It is

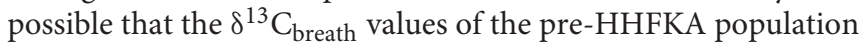
was influenced by food choices from the Hispanic students in the Valenzuela study, which comprised $31 \%$ of the analyzed samples listed here. Valenzuela et al. reported that Hispanic students, in their entire study, had significantly higher servings per week of sweetened beverages compared to non-Hispanic White students (31).

Since we did not record the ethnicities of our study population and we know that the overall high school student population was non-Hispanic White (49\%) we wanted to try to mitigate the potential effect of differences in ethnic groups represented in the Valenzuela study (35). When we compared $\delta^{13} \mathrm{C}_{\text {breath }}$ samples from only the non-Hispanic White students in the Valenzuela study to our study, we still saw that there was a significant difference between the two time periods. These results suggest that our study population were incorporating greater contributions of $\mathrm{C}_{3}$ carbohydrates (fruits, vegetables, and whole grain sources) that are consistent with the changes outlined in the HHFKA. Additionally, our findings are supported by Liu et al.'s most recent paper that examined dietary surveys from 2003-2004 and 2017-2018 among 20,905 school age children (ages 519 years old) and found that children consuming food with poor diet quality from school meals decreased by half [55.6\% (2003-2004) to $24.4 \%$ (2017-2018)] and were attributed to increases in whole grains and fruits and decreased 
sugar sweetened beverages (36) consistent with the changes outlined in HHFKA.

Our comparison of $\delta^{13} \mathrm{C}_{\text {breath }}$ is one of the first studies to examine the use of a non-invasive biomarker to assess broad types of foods that students consumed before and after the implementation of the HHKFA. We acknowledge that our study assessed a small population of high school aged students compared to other diet studies and had some limitations (student food recalls, ethnic demographic information was not taken, and the same students from the Valenzuela study were not enrolled). Despite these limitations, we have matched our comparison group to the best of our abilities (high school aged students, within the same public school district, similar high school ethnic demographics) and our findings can be considered more preliminary in the context of policy implementation; however, our work highlights a useful technique that can assess changes in dietary carbohydrate sources. Specifically, our study highlights the $\mathrm{C}_{4}$-to $\mathrm{C}_{3}$ change in carbohydrate sources before and after HHFKA and is consistent with the literature supporting the implementation of act. Specifically, the studies that have shown that students are consuming greater proportions of fruits, vegetables, and whole grains in their entrées (36-38), after HHFKA, contributing to the overall positive impact that the program has had. It is interesting to note that we also saw significant differences between the $\delta^{13} \mathrm{C}_{\text {breath }}$ values in the $\mathrm{AD}$ and $\mathrm{AB}$ samples compared to the Valenzuela et al.'s AM beath samples. Perhaps these findings represent an overall change in diet and food selection preferences from 2009-2010 to 2016 or perhaps, that lunch represents a larger proportional input to breath samples later in the day. However, we have no data, nor have there been specific published studies that would allow us to test this specific hypothesis, but we feel this is an interesting question that deserves further consideration.

\section{CONCLUSIONS}

This study has shown that $\delta^{13} \mathrm{C}$ measurements of breath samples can provide insight into the food choices and diets of American high school adolescents. We observed that school lunch can have an impact on a student's diet and that $\mathrm{AL} \delta^{13} \mathrm{C}_{\text {breath }}$ samples have significantly changed after the implementation of HHFKA. While stable isotope analyses of breath samples are useful in understanding an individual's diet, there are application limitations. Stable isotopes provide us with general information related to the broad characterization of different food types or sources. $\delta^{13} \mathrm{C}$ measurements allow us to distinguish food groups based on photosynthetic pathways; however, they do not allow us to differentiate an apple from an orange, both $\mathrm{C}_{3}$ food sources. These broad distinctions may have more local applications in the Americas, as beet sugars would have similar $\delta^{13} \mathrm{C}$ values to other $\mathrm{C}_{3}$ food sources. Isotopes alone offer broad dietary information and in combination with dietary recall methodologies could provide specificity to those isotope values while also confirming food choices on the questionnaires.

We would encourage researchers to continue to explore the use of stable isotope analyses of human samples, especially fingernail clippings, hair samples, and saliva as they can be collected non-invasively from study subjects and reflect short and long term dietary inputs. Compound specific isotope analyses of these tissues is another area that should also be examined, as $\delta^{13} \mathrm{C}$ measurements of individual amino acids may provide additional insight and specificity to broad characterization of food types (39). While our study focused on adolescent populations and the role of the school lunch program, we believe that this application may have significant benefits to childhood obesity and diabetic medical studies.

\section{DATA AVAILABILITY STATEMENT}

The raw data supporting the conclusions of this article will be made available by the authors, without undue reservation.

\section{ETHICS STATEMENT}

The studies involving human participants were reviewed and approved by University of Utah's Institutional Review Board. Written informed consent to participate in this study was provided by the participants' legal guardian/next of kin.

\section{AUTHOR CONTRIBUTIONS}

CM, SR, CC, and JE designed the research. CM, SR, and CC conducted the research. CM analyzed the data and wrote the article. LV and JE helped with comments in the writing of article. CM, LV, and JE had primary responsibility for final content. All authors contributed to the article and approved the submitted version.

\section{FUNDING}

Funding for CM during manuscript preparation was supported by funding from the National Institute of General Medical Sciences K12 GM08821.

\section{ACKNOWLEDGMENTS}

We would like to thank the volunteers and administration at Highland High School and the Salt Lake City School District, for their participation and allowing us to conduct our study at their school. We also thank Dr. Suvankar Chakraborty and the SIRFER facility at the University of Utah for use of their facilities and technical expertise.

\section{SUPPLEMENTARY MATERIAL}

The Supplementary Material for this article can be found online at: https://www.frontiersin.org/articles/10.3389/fmed. 2021.697557/full\#supplementary-material 


\section{REFERENCES}

1. Ogden CL, Carroll MD, Kit BK, KM F. Prevalence of childhood and adult obesity in the United States, 2011-2012. J Am Med Assoc. (2014) 311:80614. doi: $10.1001 /$ jama.2014.732

2. Hawkes C. Uneven dietary development: linking the policies and processes of globalization with the nutrition transition, obesity and diet-related chronic diseases. Glob Health. (2006) 2:4. doi: 10.1186/1744-8603-2-4

3. $\mathrm{Hu} \mathrm{FB}$. Globalization of food patterns and cardiovascular disease risk. Am Heart Assoc. (2008) 118:19134. doi: 10.1161/CIRCULATIONAHA.108.808493

4. Freedman DS, Mei Z, Srinivasan SR, Berenson GS, Dietz WH. Cardiovascular risk factors and excess adiposity among overweight children and adolescents: The Bogalusa Heart Study. J Pediatr. (2007) 150:12-7.e2. doi: 10.1016/j.jpeds.2006.08.042

5. Li C, Ford ES, Zhao G, Mokdad AH. Prevalence of pre-diabetes and its association with clustering of cardiometabolic risk factors and hyperinsulinemia among U.S. Adolesc Diabetes Care. (2009) 32:342. doi: $10.2337 / \mathrm{dc} 08-1128$

6. Cullen KW, Zakeri I. The youth/adolescent questionnaire has low validity and modest reliability among low-income African-American and hispanic seventh- and eighth-grade youth. J Am Dietetic Assoc. (2004) 104:14159. doi: $10.1016 /$ j.jada.2004.06.022

7. Borradaile KE, Foster GD, May H, Karpyn A, Sherman S, Grundy $\mathrm{K}$, et al. Associations between the youth/adolescent questionnaire, the youth/adolescent activity questionnaire, and body mass index $\mathrm{z}$ score in lowincome inner-city fourth through sixth grade children. Am J Clin Nutr. (2008) 87:1650-5. doi: 10.1093/ajen/87.6.1650

8. Thomson CA, Giuliano A, Rock CL, Ritenbaugh CK, Flatt SW, Faerber $S$, et al. Measuring dietary change in a diet intervention trial: comparing food frequency questionnaire and dietary recalls. Am J Epidemiol. (2003) 157:754-62. doi: 10.1093/aje/kwg025

9. Hedrick VE, Davy BM, Wilburn GA, Jahren AH, Zoellner JM. Evaluation of a novel biomarker of added sugar intake $(\delta 13 \mathrm{C})$ compared with selfreported added sugar intake and the Healthy Eating Index-2010 in a community-based, rural US sample. Public Health Nutr. (2016) 19:42936. doi: $10.1017 /$ S136898001500107X

10. Jahren AH, Bostic JN, Davy BM. The potential for a carbon stable isotope biomarker of dietary sugar intake. J Anal Atomic Spectr. (2014) 29:795816. doi: 10.1039/C3JA50339A

11. Martínez del Rio C, Wolf N, Carleton SA, Gannes LZ. Isotopic ecology ten years after a call for more laboratory experiments. Biol Rev. (2009) 84:91111. doi: 10.1111/j.1469-185X.2008.00064.x

12. Buchardt B, Bunch V, Helin P. Fingernails and diet: stable isotope signatures of a marine hunting community from modern Uummannaq, North Greenland. Chem Geol. (2007) 244:316-29. doi: 10.1016/j.chemgeo.2007.06.022

13. Cerling TE, Wittemyer G, Rasmussen HB, Vollrath F, Cerling CE, Robinson TJ, et al. Stable isotopes in elephant hair document migration patterns and diet changes. Proc Natl Acad Sci USA. (2006) 103:3713. doi: 10.1073/pnas.0509606102

14. Nardoto GB, Silva S, Kendall C, Ehleringer JR, Chesson LA, Ferraz ESB, et al. Geographical patterns of human diet derived from stable-isotope analysis of fingernails. Am J Phys Anthropol. (2006) 131:137-46. doi: 10.1002/ajpa.20409

15. O'Connell TC, Hedges REM, Healey MA, Simpson AHRW. Isotopic comparison of hair, nail and bone: modern analyses. J Archaeol Sci. (2001) 28:1247-55. doi: 10.1006/jasc.2001.0698

16. O'Brien DM, Niles KR, Black J, Schoeller DA. The breath carbon isotope ratio reflects short-term added-sugar intake in a dose-response, crossover feeding study of 12 healthy adults. J Nutr. (2021) 151:628-35. doi: 10.1093/jn/ nxaa352

17. Ehleringer JR, Covarrubias Avalos S, Tipple BJ, Valenzuela LO, Cerling TE. Stable isotopes in hair reveal dietary protein sources with links to socioeconomic status and health. Proc Natl Acad Sci USA. (2020) 117:2004451. doi: 10.1073/pnas.1914087117

18. Petzke KJ, Boeing H, Metges CC. Choice of dietary protein of vegetarians and omnivores is reflected in their hair protein $13 \mathrm{C}$ and $15 \mathrm{~N}$ abundance. Rapid Commun Mass Spectr. (2005) 19:1392-400. doi: 10.1002/rcm.1925
19. Cook CM, Alvig AL, Liu YQ, Schoeller DA. The natural 13C abundance of plasma glucose is a useful biomarker of recent dietary caloric sweetener intake. J Nutr. (2010) 140:333-7. doi: 10.3945/jn.109.114777

20. Farquhar GD, Ehleringer JR, Hubick KT. Carbon isotope discrimination and photosynthesis. Ann Rev Plant Physiol Plant Mol Biol. (1989) 40:50337. doi: $10.1146 /$ annurev.pp.40.060189.002443

21. Valenzuela LO, Chesson LA, Bowen GJ, Cerling TE, Ehleringer JR. Dietary heterogeneity among Western industrialized countries reflected in the stable isotope ratios of human hair. PLoS ONE. (2012) 7:e34234. doi: 10.1371/journal.pone.0034234

22. Chesson LA, Podlesak DW, Thompson AH, Cerling TE, Ehleringer JR. Variation of hydrogen, carbon, nitrogen, and oxygen stable isotope ratios in an American diet: fast food meals. J Agric Food Chem. (2008) 56:408491. doi: $10.1021 /$ jf 0733618

23. O'Brien DM. Stable isotope ratios as biomarkers of diet for health research. Ann Rev Nutr. (2015) 35:565-94. doi: 10.1146/annurev-nutr071714-034511

24. Jahren AH, Kraft RA. Carbon and nitrogen stable isotopes in fast food: signatures of corn and confinement. Proc Natl Acad Sci USA. (2008) 105:17855-60. doi: 10.1073/pnas.0809870105

25. Jahren AH, Saudek C, Yeung EH, Kao WL, Kraft RA, Caballero B. An isotopic method for quantifying sweeteners derived from corn and sugar cane. Am J Clin Nutr. (2006) 84:1380-4. doi: 10.1093/ ajcn/84.6.1380

26. Haley S, Suarez N. Sugar and Sweeteners Outlook. Washington, DC: US Department of Agriculture. Economic Research Service Publication SSS-M293 (2013).

27. Schoeller D, Klein P, Watkins J, Heim T, MacLean W. 13C abundances of nutrients and the effect of variations in $13 \mathrm{C}$ isotopic abundances of test meals formulated for 13CO2 breath tests. Am J Clin Nutr. (1980) 33:237585. doi: $10.1093 / \mathrm{ajcn} / 33.11 .2375$

28. Bütz DE, Schoeller DA, Breunig E, Brassil J, Chu J, Weidmann D. Exhaled 13CO2/12CO2 delta value as a metabolic marker for metabolism in performance training. FASEB J. (2017) 31(1 Supplement):1036.18.

29. McCue MD, Passement CA, Rodriguez M. The magnitude of the naturally occurring isotopic enrichment of $13 \mathrm{C}$ in exhaled $\mathrm{CO} 2$ is directly proportional to exercise intensity in humans. Comp Biochem Physiol Part A Mol Integr Physiol. (2015) 179:164-71. doi: 10.1016/j.cbpa. 2014.08.021

30. Hedges R, Rush E, Aalbersberg W. Correspondence between human diet, body composition and stable isotopic composition of hair and breath in Fijian villagers. Isotopes Environ Health Stud. (2009) 45:117. doi: $10.1080 / 10256010802522010$

31. Valenzuela LO, O'Grady SP, Enright LE, Murtaugh M, Sweeney C, Ehleringer JR. Evaluation of childhood nutrition by dietary survey and stable isotope analyses of hair and breath. Am J Hum Biol. (2018) 30:e23103. doi: 10.1002/ajhb.23103

32. Ayliffe LK, Cerling TE, Robinson T, West AG, Sponheimer M, Passey $\mathrm{BH}$, et al. Turnover of carbon isotopes in tail hair and breath $\mathrm{CO} 2$ of horses fed an isotopically varied diet. Oecologia. (2004) 139:1122. doi: $10.1007 / \mathrm{s} 00442-003-1479-\mathrm{x}$

33. USDA - Food and Nutrition Service. School Meals - Healthy, Hunger-Free Kids Act. (2016). Available from: https://www.fns.usda.gov/school-meals/healthyhunger-free-kids-act (accessed January 12, 2018).

34. Bowling DR, Pataki DE, Ehleringer JR. Critical evaluation of micrometeorological methods for measuring ecosystematmosphere isotopic exchange of CO2. Agric For Meteorol. (2003) 116:159-79. doi: 10.1016/S0168-1923(03)00006-6

35. Salt Lake City School District. School Profile - Highland High School. Salt Lake City, UT: Salt Lake City School District 2016 (2016).

36. Liu J, Micha R, Li Y, Mozaffarian D. Trends in food sources and diet quality among US children and adults, 2003-2018. JAMA Netw Open. (2021) 4:e215262. doi: 10.1001/jamanetworkopen.2021.5262

37. Schwartz MB, Henderson KE, Read M, Danna N, Ickovics JR. New school meal regulations increase fruit consumption and do not increase total plate waste. Childhood Obesity. (2015) 11:242-7. doi: 10.1089/ chi.2015.0019 
38. Johnson DB, Podrabsky M, Rocha A, Otten JJ. Effect of the healthy hunger-free kids act on the nutritional quality of meals selected by students and school lunch participation rates. JAMA Pediatr. (2016) 170:e153918. doi: 10.1001/jamapediatrics.201 5.3918

39. Whiteman JP, Elliott Smith EA, Besser AC, Newsome SD. A guide to using compound-specific stable isotope analysis to study the fates of molecules in organisms and ecosystems. Diversity. (2019) 11:8. doi: 10.3390/ d11010008

Conflict of Interest: The authors declare that the research was conducted in the absence of any commercial or financial relationships that could be construed as a potential conflict of interest.
Publisher's Note: All claims expressed in this article are solely those of the authors and do not necessarily represent those of their affiliated organizations, or those of the publisher, the editors and the reviewers. Any product that may be evaluated in this article, or claim that may be made by its manufacturer, is not guaranteed or endorsed by the publisher.

Copyright (c) 2022 Mancuso, Cornwall, Robinson, Valenzuela and Ehleringer. This is an open-access article distributed under the terms of the Creative Commons Attribution License (CC BY). The use, distribution or reproduction in other forums is permitted, provided the original author(s) and the copyright owner(s) are credited and that the original publication in this journal is cited, in accordance with accepted academic practice. No use, distribution or reproduction is permitted which does not comply with these terms. 